\title{
Analysis of Lung Ground-glass Nodules From the Perspective of Inflammation-to-cancer Transition Based on II-6 Level and Clinical Features
}

Changxing Shen ( $\nabla$ changxing9737@126.com)

Tongji University Tenth People's Hospital: Shanghai Tenth People's Hospital https://orcid.org/00000003-3076-4143

\section{Qing Xia}

Tongji University Tenth People's Hospital: Shanghai Tenth People's Hospital

\section{Zhuang Li}

Tongji University Tenth People's Hospital: Shanghai Tenth People's Hospital

\section{Jing Wen}

Tongji University Tenth People's Hospital: Shanghai Tenth People's Hospital

\section{Hong Zhai}

Tongji University Tenth People's Hospital: Shanghai Tenth People's Hospital

\section{Chuanwu Cao}

Tongji University Tenth People's Hospital: Shanghai Tenth People's Hospital

\section{Fei Wang}

Tongji University Tenth People's Hospital: Shanghai Tenth People's Hospital

\section{Lai Wang}

Tongji University Tenth People's Hospital: Shanghai Tenth People's Hospital

\section{Ming Li}

Tongji University Tenth People's Hospital: Shanghai Tenth People's Hospital

\section{Lijuan Zhang}

Tongji University School of Medicine

\section{Lihong Fan}

Tongji University Tenth People's Hospital: Shanghai Tenth People's Hospital

\section{Research}

Keywords: lung ground glass nodule (GGN), interleukin-6 (IL-6), T helper cell, inflammation, canceration

Posted Date: August 3rd, 2021

DOI: https://doi.org/10.21203/rs.3.rs-751180/v1 
License: (c) (i) This work is licensed under a Creative Commons Attribution 4.0 International License. Read Full License 


\section{Abstract}

Objective $\$ To explore the potential impact of interleukin-6 (IL-6) in promoting the development and progression of lung ground-glass nodules (GGN) based on multiple clinical features using multidimensional analysis (MDA).

Methods: Sample collected from data taken from patients with lung GGN who received treatment in Shanghai Tenth People's Hospital, between September 2018 and September 2020. Sample data were grouped according to GGN diameter as well as IL-6 levels and screened according to the solitary GGN $(\mathrm{d}<0.8 \mathrm{~cm})$ after more than one year of follow-up observation. Differences in associated complications, peripheral superoxide dismutase (SOD), IgE and T cell subsets, tumor markers, and CT malignant signs were compared between the two sample groups.

Results $₫ A$ total of 145 patients was included in the study. From the results, the diameter of GGN was $\geq 5 \mathrm{~mm}$ in 95 patients and $<5 \mathrm{~mm}$ in 50 patients. There were significant differences in peripheral IL-6 levels between the two groups $(p<0.05)$. Whereas the IL- 6 level was elevated in 53 patients, the levels were normal in 92 patients. There was a corresponding significant increase in complications such as anxiety, sleep disturbances, feeling of fatigue, and history of coronary stent implantation in the group of GGN patients with elevated levels of IL-6, when compared to the group with the normal IL-6 levels $(p<0.05)$. Peripheral SOD and IgE levels were observed to be significantly higher in the group with elevated IL-6 levels than seen in the group with normal IL- 6 levels $(p<0.05)$. In addition, there was also a significant difference in Thelper (Th) and T suppressor (Ts) cell levels between the two groups $(p<0.05)$. Levels of tumor markers such as NSE and CY21-1 were also found to be elevated in the group with elevated IL-6 levels than in the group with normal IL-6 levels $(p<0.05)$. Finally, the group with elevated II-6 levels was observed to have a higher proportion of patients with vascular convergence sign (VCS) and mixed ground-glass opacity (mGGO) as compared to the sample with normal IL-6 levels $(p<0.05)$.

Conclusion: Chronic inflammation is an important factor in the malignant transformation of GGN. IL-6 plays a significant role in promoting the formation of early lung cancer through multiple pathways, including mediating imbalance of the human mitochondrial antioxidant system and reactive elevation of $\mathrm{IgE}$, inhibiting the anti-tumor immune function of T cells, and promoting tumor tissue angiogenesis. The probability of malignant transformation is even higher in lung GGN accompanied with IL-6 elevation.

\section{Research Background}

Lung cancer is one of the malignant tumors with the highest morbidity and mortality rate worldwide [1]. With the increasing public awareness of health and wider application of low-dose spiral CT, the detection rate of lung nodules has been increased substantially [2]. The prevalence of lung ground-glass nodules (GGN) is high. Clinically, GGN presents diversely with a wide range of clinical manifestation and are prone to cancerations [3]. As a result, it is important to intensify clinical analysis of GGN and its associative 
factors responsible for lung cancer development, to prevent or improve the prognostic value of lung cancer positively.

It is generally believed that lung GGN formation is related to long-term inflammatory stimulation. Interleukin-6 (IL-6) is a common proinflammatory factor [4] and is closely associated with the development and prognosis of lung cancer $[5,6]$. The goal of this study is to analyze inflammatory factors and clinical features of lung GGN and explore the role of inflammation in the biological behavior of lung GGN.

\section{Subjects And Methods}

\section{Subjects}

Clinical data of patients with lung GGN who received treatment in Shanghai Tenth People's Hospital (Shanghai, China) between September 2018 and September 2020 were collected. A total of 145 patients with lung GGN were included in the study. The inclusion criteria were patients with lung GGN of a minimum diameter of 0.8. Patients must have been followed up for more than a year. Patients must have undergone a high-resolution CT (HRCT) scan, and excluded for lung nodules arising from other reasons such as malignant tumor metastasis or acute infective diseases.

The research protocol was approved by the ethics committee of the said hospital, and informed consent was signed by all participating subjects.

\section{Methods}

\section{Data collection}

Sample data taken from GGN patients included: (1) patient's general information, such as sex, age, smoking history, and family history of lung cancer; (2) clinical manifestations such as cough, chest pain, shortness of breath, fatigue, diarrhea, or constipation, and sleep disturbances; (3) past medical histories including hypertension, diabetes, chronic pulmonary disease, chronic liver disease, chronic kidney disease, cardiocerebrovascular disease and malignant tumors; and (4) investigations included chest CT and laboratory tests consisting of $\mathrm{T}$ cell subset analysis, inflammatory markers, humoral immunology, tumor markers, and adenosine triphosphate (ATP) level of peripheral mononuclear cells.

\section{Grouping}

Samples were classified into two groups: patients with $\mathrm{GGN} \geq 5 \mathrm{~mm}$ in diameter and those with $\mathrm{GGN}<5 \mathrm{~mm}$ in diameter. Comparison based on levels of inflammatory mediators were made between the two groups. Results showed significant differences in IL-6 levels. Consequently, patients were further classified into those with elevated levels of IL-6, and those with normal levels of IL-6, with $5.3 \mathrm{pg} / \mathrm{ml}$ considered as the higher limit of normal. 


\section{Index analysis}

Differences in baseline data, symptoms, complications, imaging characteristics of the nodules, peripheral TNF-a, humoral immunology (IgG and IgE), cell immunology (percentage of total T cells and T helper (Th) / T suppressor cell (Ts) ratio), superoxide dismutase (SOD), and tumor markers (CEA, NSE and CY21-1) were compared between the IL- 6 elevated group and the group with normal IL- 6 levels. All the above investigations were done in Shanghai $10^{\text {th }}$ people's hospital using the following normal reference values: TNF-a: 0-4.6 pg/ml, IgG: 7-16 g/ml, IgE: $<100 \mathrm{~g} / \mathrm{ml}$, total T cell: 50-84 \%, Th: $27-51 \%$, Ts: $15-44 \%$, SOD: 110-215 U/L, CEA: $<5.2 \mathrm{ng} / \mathrm{ml}$, NSE: $<16.3 \mathrm{ng} / \mathrm{ml}$, and CY21-1: $<3.3 \mathrm{ng} / \mathrm{ml}$. Chest CT scan was performed by the department of radiology of the said hospital, and the results were reported by at least two senior radiologists of the radiology department.

\section{Statistical methods}

All statistical data were analyzed by using SPSS 22.0. Measurement of data was expressed as mean and a standard deviation (SD), and verified by t-test. Sample data was expressed as a percentage and verified by the chi-square test. $P$ values $<0.05$ were considered statistically significant.

\section{Results}

Baseline data, clinical manifestations, complications, and laboratory findings.

Out of the 145 included patients, 95 had GGN $\geq 5 \mathrm{~mm}$, and 50 had $G G N<5 \mathrm{~mm}$. The study found no significant difference in the baseline data between the two groups. There was also no significant difference in sex, age, IL-4, IL-8, and TNF-a levels between the two groups. However, the study found significant differences in IL-6 levels between the two groups $(p<0.05)$ (Table 1). While IL-6 was found to be elevated in 53 patients, levels were normal in 92 patients. Details of the symptoms, complications, and laboratory findings are shown in Table 2. The proportion of GGN patients with vascular convergence sign (VCS) and mixed ground-glass opacity (mGGO) in the group with elevated levels of IL-6 was significantly higher than the group with normal IL-6 levels $(p<0.05)$ (Table 3). 
Table 1

Comparison of inflammatory factor levels between patients with different sizes of lung GGN

\begin{tabular}{|llll|}
\hline Item & $\begin{array}{l}\text { GGN }(\mathbf{d} \geq 5 \mathrm{~mm}) \\
\boldsymbol{n}=95\end{array}$ & $\begin{array}{l}\text { GGN }(\mathbf{d}<5 \mathrm{~mm}) \\
\boldsymbol{n}=\mathbf{5 0}\end{array}$ & P value \\
\hline Age $( \pm \mathrm{SD})(\mathrm{yr})$ & $56.92 \pm 13.25$ & $54.10 \pm 12.21$ & 0.58 \\
\hline Sex $(\mathrm{M} / \mathrm{F})$ & $59 / 36$ & $29 / 21$ & 0.72 \\
\hline IL-6 $(\mathrm{pg} / \mathrm{ml})$ & $11.41 \pm 16.10$ & $2.80 \pm 1.84$ & $<0.001^{*}$ \\
\hline IL-8 $(\mathrm{pg} / \mathrm{ml})$ & $40.78 \pm 5.72$ & $38.34 \pm 6.64$ & 0.68 \\
\hline $\mathrm{TNF}-\mathrm{a}(\mathrm{pg} / \mathrm{ml})$ & $5.01 \pm 3.79$ & $4.42 \pm 3.21$ & 0.08 \\
\hline $\mathrm{IL}-4(\mathrm{pg} / \mathrm{ml})$ & $1.42 \pm 0.88$ & $1.56 \pm 0.75$ & 0.42 \\
\hline
\end{tabular}


Table 2

Comparison of the clinical features between GGN patients with different IL-6 levels

\begin{tabular}{|c|c|c|c|}
\hline Item & $\begin{array}{l}\text { IL-6 elevation group } \\
n=53\end{array}$ & Normal IL-6 group $n=92$ & $P$ value \\
\hline Case number & 53 & 92 & \\
\hline Age & $57.4 \pm 13.9$ & $55.1 \pm 12.3$ & 0.18 \\
\hline Sex (Male/Female) & $32 / 21$ & $56 / 36$ & 1.01 \\
\hline Smoking history (yes/no) & $3 / 50$ & $5 / 87$ & 0.84 \\
\hline Malignant tumor (yes/no) & $2 / 51$ & $3 / 89$ & 0.73 \\
\hline Lung cancer family history (yes/no) & $1 / 52$ & $2 / 90$ & 0.86 \\
\hline Cough (yes/no) & $1 / 52$ & $2 / 90$ & 1.01 \\
\hline Chest suffocation and pain (yes/no) & $1 / 52$ & $1 / 91$ & 1.00 \\
\hline Fatigue (yes/no) & $23 / 30$ & $4 / 88$ & $0.02 *$ \\
\hline GI dysfunction (yes/no) & $26 / 27$ & $12 / 80$ & $0.03 *$ \\
\hline Sleep disturbance (yes/no) & $30 / 23$ & $10 / 82$ & $0.028 *$ \\
\hline Anxiety (yes/no) & $40 / 13$ & $23 / 69$ & $0.01 *$ \\
\hline Hypertension (yes/no) & $10 / 43$ & $19 / 73$ & 0.92 \\
\hline Diabetes (yes/no) & $8 / 45$ & $6 / 86$ & 0.78 \\
\hline Chronic liver disease (yes/no) & $2 / 51$ & $1 / 91$ & 1.05 \\
\hline Chronic kidney disease (yes/no) & $2 / 51$ & $0 / 92$ & 0.29 \\
\hline Chronic pulmonary disease (yes/no) & $11 / 42$ & $17 / 75$ & 0.49 \\
\hline Cardiocerebrovascular disease (yes/no) & $9 / 44$ & $12 / 80$ & 0.79 \\
\hline Coronary stenting (yes/no) & $7 / 46$ & $2 / 90$ & $0.035^{\star}$ \\
\hline \multicolumn{4}{|l|}{ Laboratory findings } \\
\hline SOD (U/L) & $238.33 \pm 25.14$ & $170.92 \pm 35.29$ & $0.001 *$ \\
\hline TNF-a (pg/ml) & $5.89 \pm 6.91$ & $2.54 \pm 1.82$ & $0.001^{*}$ \\
\hline $\lg -\mathrm{G}(\mathrm{g} / \mathrm{ml})$ & $15.3 \pm 8.15$ & $13.8 \pm 7.49$ & 0.23 \\
\hline lg-E (IU/ml) & $117.37 \pm 163.07$ & $77.69 \pm 88.49$ & $0.048^{*}$ \\
\hline Total T cell (\%) & $66.57 \pm 10.72$ & $66.84 \pm 12.62$ & 0.43 \\
\hline Th (\%) & $35.81 \pm 8.96$ & $39.8 \pm 9.85$ & $0.02^{\star}$ \\
\hline
\end{tabular}




\begin{tabular}{|llll|}
\hline Item & $\begin{array}{l}\text { IL-6 elevation group } \\
\boldsymbol{n}=\mathbf{5 3}\end{array}$ & Normal IL-6 group $\boldsymbol{n}=\mathbf{9 2}$ & P value \\
\hline Ts $(\%)$ & $30.76 \pm 9.99$ & $25.49 \pm 8.10$ & $0.01^{*}$ \\
\hline NSE $(\mathrm{ng} / \mathrm{ml})$ & $22.42 \pm 4.77$ & $16.62 \pm 4.55$ & $0.001^{*}$ \\
\hline CEA $(\mathrm{ng} / \mathrm{ml})$ & $3.34 \pm 0.46$ & $2.98 \pm 0.37$ & 0.36 \\
\hline CY $21-1(\mathrm{ng} / \mathrm{ml})$ & $5.66 \pm 0.67$ & $3.02 \pm 0.48$ & $0.01^{*}$ \\
\hline
\end{tabular}

Table 3

Comparison of CT imaging features between lung GGN patients with different IL-6 levels

\begin{tabular}{|llll|}
\hline Item & IL-6 elevation group $\boldsymbol{n = 5 3}$ & Norma IL-6 group & P value \\
& & $n=92$ & \\
\hline VCS (yes/no) & $39 / 14$ & $21 / 71$ & $0.03^{\star}$ \\
\hline Calcification (yes/no) & $2 / 51$ & $3 / 89$ & 0.67 \\
\hline Vacuole sign (yes/no) & $5 / 48$ & $2 / 90$ & 0.33 \\
\hline Pleural indentation (yes/no) & $1 / 51$ & $0 / 92$ & 1.02 \\
\hline Simple GGN (\%) & $11 / 53$ & $12 / 92$ & 0.21 \\
\hline Mixed GGN (\%) & $40 / 53$ & $60 / 92$ & $0.04^{\star}$ \\
\hline Solid nodule (\%) & $2 / 53$ & $20 / 92$ & 0.08 \\
\hline Nodule (d $\geq 0.5 c m) ~(\%)$ & $36 / 53$ & $37 / 92$ & $0.04 *$ \\
\hline Simple nodule (\%) & $2 / 53$ & $4 / 92$ & 0.88 \\
\hline Multiple nodules (\%) & $51 / 53$ & $88 / 92$ & 0.96 \\
\hline Upper + middle lobe (\%) & $33 / 53$ & $32 / 92$ & 0.16 \\
\hline Lower lobe (\%) & $20 / 53$ & $60 / 92$ & 0.11 \\
\hline VCS, vascular convergence sign & & \\
\hline
\end{tabular}

\section{Discussion}

The release of reactive oxygen species (ROS) from the mitochondria of inflammatory cells under chronic inflammatory conditions could directly cause a genotoxic effect and damage to tissues, thereby initiating and promoting tumor development, invasion, and migration [7]. As a response, the expression of SOD released from mitochondria to the peripheral blood is increased [8, 9]. Increased SOD expression was found to be related to the upregulation of matrix metalloprotein (MMP), hence blocking SOD could partly reverse epithelial-mesenchymal transition (EMT) and migration of A549 cells [10 ]. Other studies found 
that the content of SOD in tissues of adenocarcinoma of the lung was significantly higher than that in adjacent normal tissues [11]. We found that SOD levels in the IL-6 elevated level group were significantly higher than those in the normal IL-6 level group. In addition, GGN in the group with elevated levels of IL-6 exhibited more malignant signs on imaging, suggesting that lung GGN with SOD elevation may have a more malignant transformation potential [12].

IgE can provide a protective effect on the mucosal epithelium exposed to carcinogenic environments. It was found that exposure of the mouse skin to benzopyrene could produce a local IgE response, which induced the basophilic granulocyte-mediated anti-tumor effect to clear cancerous cells following DNA damage by cancerogenic substances. When the IgE response was blocked, the cancerous tissue induced by the carcinogenic substances grew even faster $[13,14]$. It was found in our study that the IgE level in the GGN patients of the IL- 6 elevated group was increased significantly. IgE could promote the transformation of the activated macrophages to the proinflammatory phenotype [15], and enhance the anti-tumor proinflammatory signal and promote the killing effect of human mononuclear cells on tumor cells [16]. Therefore, a reactive elevation of IgE may be a tumor protective mechanism in early canceration of lung GGN. However, this postulate could on the other hand imply that GGN lesions with an elevation of IL-6 and IgE could be associated with an increased risk of malignancy.

We found from the sample of GGN patients with elevated levels of IL-6 that, while the levels of Ts cells were increased, that of Th cells was decreased significantly. IL- 6 has a role in promoting tumor formation $[17,18]$. Myeloid-derived suppressor cells (MDSC) are a group of cells generated in the process of tumor progression, that function to inhibit T cells and natural killer (NK) cells, promoting tumor progression. IL-6 is an important regulatory factor aggregated and activated by MDSC, resulting in the inhibition of adaptive immunity [19]. Studies demonstrated that CD40 of upregulated MDSC could induce T cell tolerance in tumor-bearing mice. In addition, MDSC could stimulate M2-like macrophages to produce large amounts of IL-1 to promote tumor progression and induce Treg cell-mediated immune suppression. Under the stimulation of tumor-derived transforming growth factor TGF- $\beta$, MDSC upregulates the expression of peripheral ATP hydrolase- 1 and nucleotidase and catalyzes the degradation of ATP into adenosine [20], which has an immunosuppressive effect on T and NK cells, thus reducing their killing effect on tumor cells. Other studies [21] also found that IL-6 could inhibit T cell activation in tumors, suggesting that IL- 6 may be an important factor in inhibiting anti-tumor immunity of T cells.

Chronic inflammation and decreased immune function are common phenomena of immunosenescence [22]. Most GGN patients in our study were between 50 and 60 years of age, which is a period of quick immunosenescence. Therefore, complications in GGN patients with IL-6 elevation should not be ignored. Clinicians should first assess whether complications of the patients would produce a negative impact on their lung GGN, such as chronic intestinal diseases. Recent studies have demonstrated a close relationship between the gut and lung [23]. For instance, patients with chronic pulmonary diseases do not only present microecological changes in the respiratory tract but their gut microbiota as well. Gut microbiota metabolites such as short-chain fatty acids (SCFAs) have systemic anti-inflammatory effects. Destruction of intestinal microecology will lead to GI dysfunction and imbalance between anti- and pro- 
inflammatory cells of the human body [24]. Gut microbiota also undergoes abnormal changes in patients with anxiety. In addition, metabolites from intestinal flora have important impacts on human inflammatory responses [25]. Both IL-6 and TNF-a mediators of pro-inflammation in the inflammatory mechanism of the gut-lung axis as well as gut-brain axis $[24,26]$. Coronary stenting is quite common in lung GGN patients with elevated levels of IL-6, which may reflect that inflammatory mediators could be implicated in aggravating coronary arterial damage. Higher levels of IL- 6 and TNF-a participate in coronary arterial damage, as well as in the development and progression of tumors [27, 28]. Besides, IL- 6 also mediates the systemic inflammatory response of cancer patients $[29,30]$. For this reason, lung GGN is to some extent a systemic disease accompanied by other complications. Regulating gut microbiota and controlling inflammation are important critical ways to prevent GGN canceration [31, 32].

It was found in our study that tumor markers were elevated in GGN patients with elevated levels of IL-6. IL-6 promoted \{had a role in promoting\} the transformation of lung tumor stem cells to foci of early canceration. In addition, combined use of the anti-IL- 6 antibody and cisplatin could destroy lung cancerlike organs, while use of cisplatin alone did not produce such an effect. A study detected the presence of positive expression of IL-6mRNA in lung cancer cells [33]. Tumor cell-derived IL-6 promotes tumor cell proliferation by promoting glycolytic metabolism of tumor cells and activating the MEK/Erk $1 / 2$ hypoxiainducible factor 1a (HIF-1a) pathway [34, 35]. IL-6 can also confer stem cell-like properties on cancer cells by activating IL-6/STAT3 signaling [36, 37]. Elevation of NSE and CY21-1 in GGN patients of IL-6 elevated group suggests that inflammation has a promoting effect on tumor development and progression [3842]. IL-6 promotes angiogenesis of early cancer tissues. It was found that the vascular endothelial growth factor receptor (VEGFR) level in non-small cell lung cancer (NSCLC) patients with elevated levels of IL-6 were even higher than that in those with normal IL- 6 levels, and IL- 6 and VEGFR were independent prognostic factors [43]. Inflammation and angiogenesis are two important features in tumorigenesis. Tumor microvascular density (MVD) was found to correlate positively with the expression of IL-6 and VEGFR in human lung adenocarcinoma tissues [44]. IL-6 and VEGFR were found to play a key role in tumor angiogenesis [45]; when IL-6 formation was inhibited, tumor infiltration and metastasis were decreased [46]. Lung GGN with VCS may most probably represent lung cancer in its early stage. This could be evident on CT imaging as gathering or displacement of a single or multiple pulmonary microvessels to the GGN lesion due to traction, disrupting the GGN lesion, or penetrating through it [47]. It is reported in the literature that the canceration rate of mixed GGN (mGGN) is more than $50 \%[48,49]$. Such canceration rate is even higher in GGN patients with IL-6 elevation and VCS, and in MGGN patients.

\section{Highlights and limitations}

To the best of our knowledge, this is the most comprehensive clinical study on factors affecting the biological behavior of lung GG by summarizing the occurrence and progression of lung GGN from the perspective of how IL-6 mediates inflammation-induced canceration. We also found that lung GGN patients with IL-6 levels elevated were more likely to be inflicted with anxiety and GI dysfunction. By inhibiting the anti-tumor immune function, tumor markers became even higher and CT imaging revealed 
more malignant signs in such patients. These findings may provide clinicians with more clues to identifying high-risk GGN at an earlier stage and preventing them from cancerous transformation.

The main limitation of the study is that the level of evidence is relatively low due to the lack of surgicalpathologic results and postoperative follow-up observations. Future research will seek to observe changes in GGN after treatment by inhibiting the inflammatory factors. This will help gain knowledge about the impact, of which inhibiting inflammatory mediators will have on cancer prevention.

\section{Conclusion}

Chronic inflammation is an important factor in promoting lung GGN and its progression to cancer. IL-6 promotes early cancer formation through multiple pathways such as by mediating imbalance of the human mitochondrial antioxidant system and reactive elevation of $\mathrm{lgE}$, inhibiting the anti-tumor immune function of T cells, and promoting tumor tissue angiogenesis. The canceration rate of lung GGN with IL-6 elevation is higher than that of lung GGN with normal IL-6.

\section{Declarations}

\section{Ethics approval and consent to participate}

Ethical Statement: The authors are accountable for all aspects of the work in ensuring that questions related to the accuracy or integrity of any part of the work are appropriately investigated and resolved. This study was approved by the Ethics Committee of Shanghai Tenth People's Hospital, approval number: SHSY-IEC-KY-4.1/21-146/01. This study is a retrospective analysis, not applicable to informed consent.

\section{Consent for publication}

Not applicable

\section{Availability of data and materials}

Not applicable

\section{Competing interests}

This study is a retrospective analysis, not applicable to informed consent.

\section{Funding}

This work was supported by the National Natural Science Foundation of China (81473469). This study was funded by Shanghai Municipal Health Planning Commission Project (No. ZHYY-ZXYJHZX-201607), the National Natural Science Foundation of China (31770131,81473469), Shanghai Shen Kang Hospital Development Center plan (SHDC12018119), Shanghai Tenth Hospital's improvement plan for NSFC 
(SYGZRPY2017014) and Scientific Research Projects of Shanghai Municipal Commission of Health and Family Planning (201840056).

\section{Authors' contributions}

The study was designed by Lihong Fan. Lai Wang developed the statistical analysis plan. Changxing Shen and Qing Xia wrote the manuscript. Zhuang Li, Fei Wang and Hong Zhai perform the research and collect data. Chuanwu Cao and Ming Li performs data management. Jing wen and Lijuan Zhang are statisticians. All authors reviewed and approved the final manuscript.

\section{Acknowledgements}

Not applicable

\section{References}

1. Siegel RL, Miller KD, Jemal A. Cancer statistics. CA: a cancer journal for clinicians $2018 \mathrm{Vol}$. 2018;68(1):7-30.

2. Chen Z, Fillmore CM, Hammerman PS, et al. Non-small-cell lung cancers: a heterogeneous set of diseases. Nature reviews Cancer. 2014;14(8):535-46.

3. Bhatt M, Kant S, Bhaskar R. Pulmonary tuberculosis as differential diagnosis of lung cancer. South.

4. HSU H S, LIN J H, HSU T, W, et al. Mesenchymal stem cells enhance lung cancer initiation through activation of IL-6/JAK2/STAT3 pathway[J]. Lung Cancer. 2012;75(2):167-77.

5. CHUANG C H, GREENSIDE P G, ROGERS Z, N, et al. Molecular definition of a metastatic lung cancer state reveals a targetable CD109-Janus kinase-Stat axis[J]. Nat Med. 2017;23(3):291-300.

6. Liu W, Wang H, Bai F, Ding L, Huang Y, Lu C, Chen S, Li C, Yue X, Liang X, Ma C, Xu L, Gao L. IL-6 promotes metastasis of non-small-cell lung cancer by up-regulating TIM-4 via NF-kB. Cell Prolif. 2020 Mar;53(3):e12776. doi:10.1111/cpr.12776. Epub 2020 Feb 5.

7. Zhang J, Song X, Cao W, et al. Autophagy and mitochondrial dysfunction in adjuvant-arthritis rats treatment with resveratrol. Sci Rep. 2016;6:32928.

8. Shao P, Guo N, Wang C, Zhao M, Yi L, Liu C, Kang L, Cao L, Lv P, Xing L, Zhang X, Shen H. Aflatoxin G1 induced TNF-a-dependent lung inflammation to enhance DNA damage in alveolar epithelial cells. J Cell Physiol. 2019 Jun;234(6):9194-206. doi:10.1002/jcp.27596. Epub 2018 Nov 27.

9. Hardeland R. Melatonin and the electron transport chain. Cell Mol Life Sci. 2017 Nov;74(21):388396. doi:10.1007/s00018-017-2615-9. Epub 2017 Aug 7.

10. Han X, Liu X, Wang X, Guo W, Wen Y, Meng W, Peng D, Lv P, Zhang X, Shen H. TNF-a-dependent lung inflammation upregulates superoxide dismutase-2 to promote tumor cell proliferation in lung adenocarcinoma. Mol Carcinog. 2020 Sep;59(9):1088-99. doi:10.1002/mc.23239. Epub 2020 Jul 16. 
11. lizuka S [Human manganese-containing superoxide dismutase: enzyme immunoassay and contents in lung cancer]. Hokkaido Igaku Zasshi. 1984 Nov;59(6):739 - 49. Japanese. PMID: 6397417.

12. Yi L, Shen H, Zhao M, et al. Inflammation-mediated SOD-2 upregulation contributes to epithelialmesenchymal transition and migration of tumor cells in aflatoxin G1-induced lung adenocarcinoma. Sci Rep. 2017;7:7953. https://doi.org/10.1038/s41598-017-08537-2.

13. McGraw JM, Havran WL. $ү \delta$ T cells and IgE team up to prevent tumors. Nat Immunol. 2018;19:7935.

14. Crawford G, Hayes MD, Seoane RC, et al. Epithelial damage and tissue $\gamma \delta T$ cells promote a unique tumor-protective IgE response. Nat Immunol. 2018;19:859-70.

15. Tsoka S, Josephs DH, Spicer JF, Karagiannis SN. IgE re-programs alternatively-activated human macrophages towards pro-inflammatory anti-tumoural states. EBioMedicine. 2019 May;43:67-81. doi: 10.1016/j.ebiom.2019.03.080. Epub 2019 Apr 5.

16. Nakamura M, Souri EA, Osborn G, Laddach R, Chauhan J, Stavraka C, Lombardi S, Black A, Khiabany A, Khair DO, Figini M, Winship A, Ghosh S, Montes A, Spicer JF, Bax HJ, Josephs DH, Lacy KE, Tsoka S, Karagiannis SN. IgE Activates Monocytes from Cancer Patients to Acquire a Pro-Inflammatory Phenotype. Cancers (Basel). 2020 Nov 15;12(11):3376. doi: 10.3390/cancers12113376.

17. Jourdan M, Veyrune J-L, De Vos J, Redal N, Couderc G. B. KleinA major role for Mcl-1 antiapoptotic protein in the IL-6-induced survival of human myeloma cells. Oncogene. 2003;22:2950-9.

18. Wegiel B, Bjartell A, Culig Z. J.L. PerssonInterleukin-6 activates PI3K/Akt pathway and regulates cyclin A1 to promote prostate cancer cell survival. Int J Cancer. 2008;122:1521-9.

19. Cui L, Chen SY, Lerbs T, Lee JW, Domizi P, Gordon S, Kim YH, Nolan G, Betancur P, Wernig G. Activation of JUN in fibroblasts promotes pro-fibrotic programme and modulates protective immunity. Nat Commun. 2020 Jun 3;11(1):2795. doi: 10.1038/s41467-020-16466-4.

20. Weber R, Groth C, Lasser S, Arkhypov I, Petrova V, Altevogt P, Utikal J, Umansky V. IL-6 as a major regulator of MDSC activity and possible target for cancer immunotherapy. Cell Immunol. 2020 Nov 29;359:104254. doi: 10.1016/j.cellimm.2020.104254. Epub ahead of print.

21. Fisher DT, Appenheimer MM. S.S. EvansThe two faces of IL-6 in the tumor microenvironment. Semin Immunol. 2014;26:38-47.

22. De Maeyer RPH, Chambers ES. The impact of ageing on monocytes and macrophages. Immunol Lett. 2020 Dec 10:S0165-2478(20)30425-9. doi: 10.1016/j.imlet.2020.12.003. Epub ahead of print.

23. Marsland BJ, Trompette A, Gollwitzer ES. The Gut-Lung Axis in Respiratory Disease. Ann Am Thorac Soc. 2015 Nov;12(Suppl 2):150-6. doi:10.1513/AnnalsATS.201503-133AW.

24. Zhang Y, Xie B, Chen X, Zhang J, Yuan S. A key role of gut microbiota-vagus nerve/spleen axis in sleep deprivation-mediated aggravation of systemic inflammation after LPS administration. Life Sci. 2020 Nov 8:118736. doi: 10.1016/j.Ifs.2020.118736. Epub ahead of print.

25. Simpson CA, Diaz-Arteche C, Eliby D, Schwartz OS, Simmons JG, Cowan CSM. The gut microbiota in anxiety and depression - A systematic review. Clin Psychol Rev. 2020 Oct 29;83:101943. doi: 10.1016/j.cpr.2020.101943. Epub ahead of print. 
26. Xie R, Jiang P, Lin L, Yu B, Wang C, Pan Y, Rao J, Wei W, Qiao Y. Association of lymphoid tissueresident commensal bacteria in mice with depressive-like behaviors induced by chronic social defeat stress. FASEB J. 2020 Jun;34(6):8310-25. doi:10.1096/fj.201902680RR. Epub 2020 Apr 25.

27. Amin MN, Siddiqui SA, Ibrahim M, Hakim ML, Ahammed MS, Kabir A, Sultana F. Inflammatory cytokines in the pathogenesis of cardiovascular disease and cancer. SAGE Open Med. 2020 Oct;20:8:2050312120965752. doi:10.1177/2050312120965752.

28. Chen J, Han L, Xu X, Tang H, Wang H, Wei B. Serum biomarkers VEGF-C and IL- 6 are associated with severe human Peripheral Artery Stenosis. J Inflamm (Lond). 2015 Aug 18;12:50. doi: 10.1186/s12950-015-0095-y.

29. Yanagawa H, Sone S, Takahashi Y, Haku T, Yano S, Shinohara T, Ogura T. Serum levels of interleukin 6 in patients with lung cancer. Br J Cancer. 1995 May;71(5):1095-8. doi:10.1038/bjc.1995.212.

30. Elisia I, Lam V, Cho B, et al. The effect of smoking on chronic inflammation, immune function and blood cell composition. Sci Rep. 2020;10:19480.

31. Li R, Huang Y, Lin J. Distinct effects of general anesthetics on lung metastasis mediated by IL6/JAK/STAT3 pathway in mouse models. Nat Commun. 2020;11:642. https://doi.org/10.1038/s41467-019-14065-6].

32. Werner-Klein M, Grujovic A, Irlbeck C, et al. Interleukin-6 trans-signaling is a candidate mechanism to drive progression of human DCCs during clinical latency. Nat Commun. 2020;11:4977. https://doi.org/10.1038/s41467-020-18701-4.

33. Ogawa H, Koyanagi-Aoi M, Otani K, Zen Y, Maniwa Y, Aoi T. Interleukin-6 blockade attenuates lung cancer tissue construction integrated by cancer stem cells. Sci Rep. 2017 Sep 26;7(1):12317. doi: 10.1038/s41598-017-12017-y.

34. Li W, Xiao J, Zhou X, Xu M, Hu C, Xu X, Lu Y, Liu C, Xue S, Nie L, Zhang H, Li Z, Zhang Y, Ji F, Hui L, Tao W, Wei B, Wang H. STK4 regulates TLR pathways and protects against chronic inflammationrelated hepatocellular carcinoma. J Clin Invest. 2015 Nov 2;125(11):4239-54. doi: 10.1172/JCl81203. Epub 2015 Oct 12.

35. Itoh $\mathrm{H}$, Kadomatsu T, Tanoue $\mathrm{H}$, et al. TET2-dependent IL-6 induction mediated by the tumor microenvironment promotes tumor metastasis in osteosarcoma. Oncogene. 2018;37:2903-20. https://doi.org/10.1038/s41388-018-0160-0.

36. Xu Z, Li L, Qian Y, et al. Upregulation of IL-6 in CUL4B-deficient myeloid-derived suppressive cells increases the aggressiveness of cancer cells. Oncogene. 2019;38:5860-72. https://doi.org/10.1038/s41388-019-0847-x.

37. Jones SA, Jenkins BJ. Recent insights into targeting the IL- 6 cytokine family in inflammatory diseases and cancer. Nat Rev Immunol. 2018;18:773-89. https://doi.org/10.1038/s41577-018-00667.

38. Li Y, Lv W, Cheng G, Wang S, Liu B, Zhao H, Wang H, Zhang L, Dong C, Zhang J. Effect of Early Normobaric Hyperoxia on Blast-Induced Traumatic Brain Injury in Rats. Neurochem Res. 2020 Nov;45(11):2723-2731. doi: 10.1007/s11064-020-03123-x. Epub 2020 Sep 9. 
39. Yu D, Liu B, Jiang G, Pei S, Pan H. Correlation of changes in serum S100ß, NSE and inflammatory factor levels with MMSE and MoCA in intracranial tumor patients with cognitive impairment. Oncol Lett. 2020 Aug;20(2):1968-72. doi:10.3892/ol.2020.11751. Epub 2020 Jun 17.

40. Tang H, Bai Y, Shen W, Wei Y, Xu M, Zhou X, Zhao J. Clinical significance of combined detection of interleukin-6 and tumour markers in lung cancer. Autoimmunity. 2018 Jun;51(4):191-198. doi: 10.1080/08916934.2018.1477133. Epub 2018 Jun 5.

41. Chang KT, Huang CY, Tsai CM, Chiu CH, Lok YY. Role of IL-6 in neuroendocrine differentiation and chemosensitivity of non-small cell lung cancer. Am J Physiol Lung Cell Mol Physiol. 2005 Sep;289(3):L438-45. doi:10.1152/ajplung.00033.2005. Epub 2005 May 13.

42. Wang B, He YJ, Tian YX, Yang RN, Zhu YR, Qiu H. Clinical utility of haptoglobin in combination with CEA, NSE and CYFRA21-1 for diagnosis of lung cancer. Asian Pac J Cancer Prev. 2014;15(22):96114. doi:10.7314/apjcp.2014.15.22.9611.

43. Jia Y, Li X, Zhao C, Jiang T, Zhao S, Zhang L, Liu X, Shi J, Qiao M, Luo J, Liu S, Han R, Chen X, Zhou C. Impact of serum vascular endothelial growth factor and interleukin- 6 on treatment response to epidermal growth factor receptor tyrosine kinase inhibitors in patients with non-small-cell lung cancer. Lung Cancer. 2018 Nov;125:22-8. doi:10.1016/j.lungcan.2018.08.025. Epub 2018 Aug 31.

44. Huang Q, Duan I, Qian X, et al. IL-17 Promotes Angiogenic Factors IL-6, IL-8, and Vegf Production via Stat1 in Lung Adenocarcinoma. Sci Rep. 2016;6:36551.

45. Bonapace L, Coissieux MM, Wyckoff J, et al. Cessation of CCL2 inhibition accelerates breast cancer metastasis by promoting angiogenesis. Nature. 2014;515:130-3.

46. Wei LH, Kuo ML, Chen CA, et al. Interleukin-6 promotes cervical tumor growth by VEGF-dependent angiogenesis via a STAT3 pathway. Oncogene. 2003;22:1517-27. https://doi.org/10.1038/sj.onc.1206226.

47. Ma E, Yang Z, Li Y, Guo Y, Yu J, Deng Y. [The solitary pulmonary tuberculous cavity and malignant cavity: comparison on multi-detector row CT]. Sheng Wu Yi Xue Gong Cheng Xue Za Zhi. 2008 Aug;25(4):903-7.

48. Gao F, Sun Y, Zhang G, Zheng X, Li M, Hua Y. CT characterization of different pathological types of subcentimeter pulmonary ground-glass nodular lesions. Br J Radiol. 2019 Feb;92(1094):20180204. doi:10.1259/bjr.20180204. Epub 2018 Oct 9.

49. Pedersen JH, Saghir Z, Wille MM, Thomsen LH, Skov BG, Ashraf H. Ground-Glass Opacity Lung Nodules in the Era of Lung Cancer CT Screening: Radiology, Pathology, and Clinical Management. Oncology (Williston Park). 2016 Mar;30(3):266-74. 